\title{
From the Desk of Executive Editor
}

(BIRDEM Med J 2018; 8(1): 87)

This peer reviewed journal is an important assortment of different articles related to various disciplines of medical and allied sciences. It welcomes original articles, review articles, meta-analysis, systemic reviews and case reports from physicians and allied professionals of different medical /scientific institutions from home and abroad. The website of the journal (www.birdemmedj.org) can be browsed conveniently and the journal can be viewed online through Google and Yahoo. It's ISSN is Print: 2305-3712, On line 2305-3720.

We have received official registration for the journal from Bangladesh Medical and Dental Council (BMDC). It has also been enrolled to BanglaJOl. Any one can browse article by searching the title. The author now can submit the manuscript online. We are also enriched with the system to enumerate number of online readers who have browsed and visited our journal through web site. The statistics is very much enthusiastic and it surely encourages us very much. In this issue we have to increase the number of original article due to available good manuscripts. It is due to encouraging response from readers and authors. This proves endorsement of quality, peer reviewing and off course timely publication of our journal.

In this issue we have highlighted "Ethical issues in biomedical research and publication" as editorial. Now onwards, the journal will be published thrice (January, May and September) in a year.

We feel tremendously buoyed by our readers' participation and their responses from all over the globe. We are very much thankful to the online readers. We also express our pristine appreciation and gratefulness to the authors who bolster our hope immensely and enrich the journal aptly with valuable articles. The editorial board and the advisory boards are eagerly looking forward to your valuable advice, suggestions and recommendations in the future. With very much appreciation to our authors, who encourage us and enrich the journal with articles of variation.

Eagerly waiting for your valuable advice and new articles.

\author{
Prof. Khwaja Nazim Uddin \\ Executive Editor \\ BIRDEM Medical Journal
}

